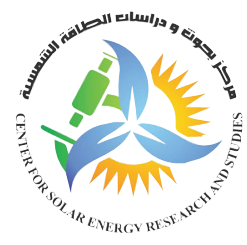

\title{
Estimation of Cooling Load Temperature Difference for Exterior Walls of Buildings Located in Tripoli, Libya
}

\author{
Abdulhakiem Ali Alhoush ${ }^{1}$, Samah Khalifa Alghoul ${ }^{1}$, Jamal \\ Sway Hawisa ${ }^{2}$ \\ ${ }^{1}$ Department of Mechanical and Industrial Engineering, University of \\ Tripoli, Tripoli, Libya \\ ${ }^{2}$ National Oil Corporation, Tripoli, Libya \\ e-mail: ${ }^{1^{*}}$ Ab.Alhoush@uot.edu.ly, ${ }^{2}$ s.alghoul@uot.edu.ly, and ${ }^{3}$ jhawisa@noc.ly
}

\begin{abstract}
A good estimate of the cooling load is one vital aspect for achieving the optimal level of comfort and energy efficiency in buildings. Due to its relative simplicity, the Cooling Load Temperature Difference (CLTD) method is still used both in education and industry for cooling load calculations. However, one downside of using this method is the limited number of walls and roofs which do not represent effectively all commonly used wall and roof constructions. In this research, a transient heat transfer model was developed to find the (CLTD) values, for the most common external walls of buildings that have widespread use in Tripoli, Libya. The Finite difference method was used to solve the governing partial differential equations with appropriate initial and boundary conditions. A MATLAB program has been developed and used to solve the system of algebraic equations produced by applying the finite difference method to the governing differential equations. A comparison has been made between the computed results and ASHRAE CLTD values. At standard conditions specified in ASHRAE handbooks for the same wall with a default composition, a reasonably good agreement was found between computed and ASHRAE CLTD values for this wall. CLTD values have been generated for three different types of walls; Hollow concrete block, Limestone block, and Hollow brick. With these values, the cooling load calculation of buildings can be easily and manually performed with more accuracy. It is also concluded from the transient analysis that the limestone block walls provide the best thermal performance for unconditioned buildings whereas hollow brick walls are better for conditioned places.
\end{abstract}

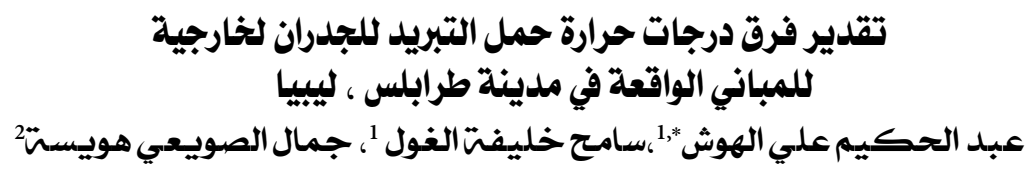

* Corresponding author 

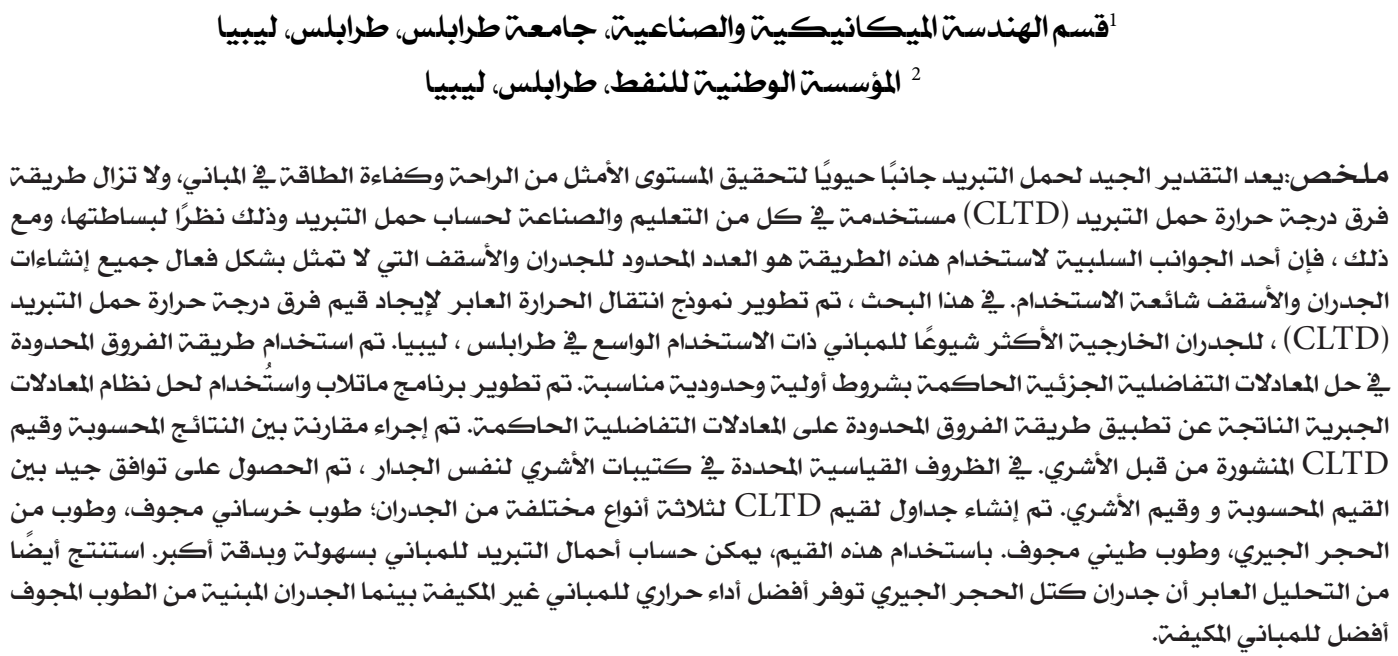

Keywords: Cooling load temperature difference, CLTD, 1-D Model, Finite difference.

This is an open access article under the CC BY-NC license (http://Attribution-NonCommercial 4.0 (CC BY-NC 4.0)).

\section{INTRODUCTION}

Air conditioning is one of the essential requirements for human beings who need to live in spaces with comfortable conditions all year around. The comfort conditions may be given as dry and wet bulb temperatures, humidity, and air velocity and its purity [1]. Recently, the use of air conditioners is becoming a standard feature in occupied spaces such as offices, shops and private houses. It is necessary to cool living spaces in summer season and to heat them in winter season in many regions worldwide [1]. Today in Libya, air conditioning systems have become an important part of everyday life for most people in commercial and residential buildings. However, the transferred energy from and to buildings through walls and roofs has direct effects on the inside conditions of the spaces, such as indoor temperature and air humidity. Therefore, it is necessary to remove some of this energy from the inside spaces in summer. This energy is called the cooling load. In winter, adding more energy to spaces inside buildings could be necessary and this amount of energy is called the heating load. These processes are being done by the air conditioning systems.

The selection of convenient air conditioning systems for buildings requires sufficiently accurate information regarding the cooling load for the buildings. In many buildings, the heat gain through the external walls and roof (fabric heat gain) constitutes a major portion of the total cooling load. Accurate estimation of cooling load due to fabric heat gain is quite complicated and time consuming as it is transient in nature due to thermal storage effects of the building mass and ever-changing external conditions [2]. Also, the dependence of fabric heat gains on the location, shape, orientation of the building, as well as the internal radiative heat transfer interactions between different surfaces of the conditioned space, further complicate the problem [2].

Over the years, several methods have been developed to estimate the building cooling load due to fabric heat gain. The nature of the actual problem is transient due to time variations in outdoor conditions and to the conversion of the heat gain into a thermal load. The determination of the thermal load associated with the heat transfer in external walls and roofs can be done by various methods developed for calculation of heat gain by using the solution of unsteady heat flow problem for the building envelope (i.e. exterior walls and roof). These solution methods can be categorized as exact and numerical solution techniques. It is very difficult to find the 
exact temperature distribution in the building elements that have a multilayered wall [1]. There are some basic calculation methods with exact and numerical solutions, which have been widely accepted over the years for the estimation of cooling loads on buildings. These are transfer function (TF), cooling load temperature difference / solar cooling load/ cooling load factors (CLTD)/ (SCL)/ (CLF), total equivalent temperature difference (TETD), and the radiant time series (RTS) methods [3]. The transfer function method (TFM) which was introduced in (1972) by ASHRAE group, is a two-step procedure. In the first step, the fabric heat gain is calculated using the conduction transfer function coefficients and in the second step, room transfer function coefficients are used to convert the heat gain into a cooling load. The accuracy of this method depends on the accuracy of the coefficients used in the two steps. Unlike the TF method, the CLTD, TETD, and RTS are a one-step procedure.

The CLTD/ SCL/ CLF method is a one-step method. In CLTD/ SCL/ CLF method, the cooling load temperature difference (CLTD) is used for calculating the cooling load due to external walls and roofs by multiplying it with the UA-value of the building element (where $U$ is the overall heat transfer coefficient of the building wall or roof and A is its surface area). Hourly values of CLTD for representative walls and roofs are available in the form of tables in ASHRAE. These CLTD values are normally generated using the TFM method for the particular walls and roofs. Thus, the CLTD/ SCL/ CLF method is much simpler than the TFM method and is therefore very widely used [1].

It is known that a procedure for CLTD values for building exterior structures established on transfer functions has been developed by ASHRAE for a typical location of $40^{\circ} \mathrm{N}$ for July 21 and typical building exterior structures in North America with fixed interior and exterior conditions. For example, the CLTD values for proper building elements are tabulated for limited types of wall or inner partition, floor, roof, or ceiling in ASHRAE. However, there are no CLTD values for the other regions of the world and other types of structures than the ones presented in ASHRAE. The structures used in other regions and climatic conditions may not be similar to those given in ASHRAE. The CLTD values in ASHRAE are being used for similar structures, and the used CLTDs are corrected for any local region in the world. However, some types of wall constructions cannot be found in ASHRAE [2], thus their CLTD values cannot be found.

The purpose of this study is the estimation of the cooling load temperature difference values for building envelopes made of materials commonly used in Libya and using Tripoli (Latitude $32.54^{\circ} \mathrm{N}$ ) weather data. The CLTD values will be generated by solving the transient heat conduction equation, and then they will be compared with the tabulated values in ASHRAE handbook. With these values, the cooling load calculation of buildings in Libya can be easily and manually accomplished with more accuracy.

\section{PROBLEM FORMULATION}

A one-dimensional transient heat transfer through a multilayered wall is considered as in Figure 1, where the total thickness of the wall is L. Each layer is homogeneous with constant thermal properties. The dimensions of the walls in $y$ and $\mathrm{z}$ directions are assumed very large; that is the reason why it is assumed that this case is one-dimensional heat transfer across the cross section of the walls. In addition, for simplicity, full contact between every two different layers in the wall (i.e., no gaps) is assumed. Also, static atmospheric air is assumed adjacent to wall surfaces, and there are no shaded walls.

It is considered that the thermal capacity of the furniture in the conditioned space to be negligible, thus neglecting the dynamic heat storage effect of the furniture and there is consequently no variation in room temperature. Thus, the room temperature $T_{r}$ is assumed to be constant. The outside surface of all walls is exposed to the atmosphere, the heat exchange at the outside surface is by both convection and radiation. Heat transfer by Sky radiation also takes place at the outside surface. Also, at the inside surface of walls, the heat transfer takes place by convection and radiation. 
It is to be noted that the solar radiation $I$, the atmospheric temperature, and the sky temperature, all vary with location and time. For the inside surface, the surface heat conductance $h_{2}$ considered to represent the combined effect of both convection and radiation.

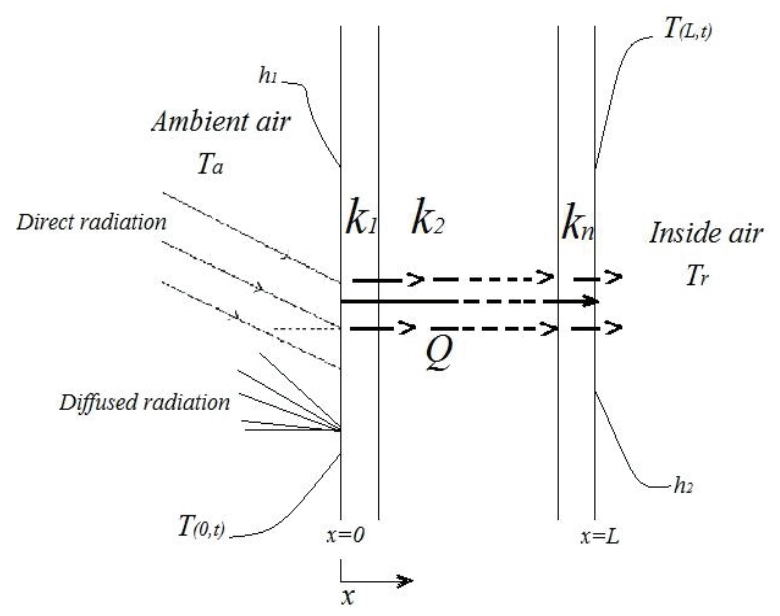

Figure (1). External wall of a building envelope

A one-dimensional transient heat transfer through layers of a wall with constant homogeneous thermal properties is presented by the following equation:

$$
\frac{\partial^{2} \mathrm{~T}}{\partial \mathrm{x}^{2}}=\frac{1}{\alpha} \frac{\partial \mathrm{T}}{\partial \mathrm{t}}
$$

Where is the thermal diffusivity ( $\alpha)$, is the thermal conductivity $\left(\alpha=k /\left(\rho C_{p}\right), m^{2} / s\right), C_{p}$ is the thermal capacity $\left(\mathrm{J} /\left(\mathrm{m}^{3} \cdot \mathrm{K}\right)\right),(\rho)$ and is the Density $\left(\mathrm{kg} / \mathrm{m}^{3}\right)$.

The outside surface of all walls is exposed to the atmosphere. Since heat exchange at the outside surface is due to both convection and radiation, then the outside boundary condition can be expressed as:

$$
-k \frac{\partial \mathrm{T}(0, \mathrm{t})}{\partial \mathrm{x}}=\mathrm{h}_{1}\left(\mathrm{~T}_{\mathrm{a}}-\mathrm{T}(0, \mathrm{t})\right)-\varepsilon \sigma_{\mathrm{c}}\left((\mathrm{T}(0, \mathrm{t}))^{4}\right)^{4}+\alpha_{\mathrm{s}} \mathrm{I}
$$

Where $h_{1}$ is the outside heat transfer coefficient $\left(\mathrm{W} /\left(\mathrm{m}^{2} \cdot \mathrm{K}\right)\right), \mathrm{T}_{\mathrm{a}}$ is the ambient air temperature $\left({ }^{\circ} \mathrm{C}\right), \varepsilon_{\mathrm{s}}$ is the outside wall surface emissivity, is a Stefan-Boltzmann constant, is the roof check coefficient ( for walls, for roofs [1]), $\alpha_{\mathrm{s}}$ is the outside wall surface absorptivity, I is the rate of radiation falling on a unit surface per unit area $\mathrm{W} / \mathrm{m}^{2}, \mathrm{~T}_{\text {sky }}$ the sky temperature $\left({ }^{\circ} \mathrm{C}\right)$, For walls $\left(\mathrm{r}_{\mathrm{c}}=0\right)$, then equation (2) can be written as follows:

$$
-\mathrm{k} \frac{\partial \mathrm{T}(0, \mathrm{t})}{\partial \mathrm{x}}=\mathrm{h}_{1}\left(\mathrm{~T}_{\mathrm{a}}-\mathrm{T}(0, \mathrm{t})\right)+\alpha_{\mathrm{s}} \mathrm{I}
$$

The surface heat transfer conductance at the inner surface of the wall is considered to combine the effects of both convection and radiation, where the total heat transfer at the inner surface is determined by adding the contributions of both heat transfer mechanisms. For simplicity and convenience, this is often done by defining a combined heat transfer coefficient [4]. Then the inside boundary condition can be written as equation (3). Note that, for convenience, $h_{2}$ will be used instead of $h_{\text {combined }}$. 


$$
-k \frac{\partial T(L, t)}{\partial x}=h_{2}\left(T(L, t)-T_{r}\right)
$$

Equation (1) is subject to the initial condition:

$$
\mathrm{T}(\mathrm{x}, 0)=\mathrm{T}_{\mathrm{i}}, \quad 0 \leq \mathrm{x} \leq \mathrm{L}
$$

\section{MATERIALS AND METHODS}

\subsection{Insolation on tilted surfaces (vertical walls)}

The amount of radiation incident on an inclined surface is the algebraic sum of the direct radiation reflected from the ground and diffuse sky radiation incident on a surface and is usually called global radiation [5]. If an unshaded flat surface is titled at an angle $\beta$ (the angle between the horizontal and plane), the global irradiance, $\mathrm{I}_{\text {glo,tilt }}$, on the tilted plane is defined as follows:

$$
\mathrm{I}_{\mathrm{glo}, \mathrm{tit}}=\mathrm{I}_{\mathrm{dir}} \cos \theta_{\mathrm{i}}+\mathrm{I}_{\mathrm{dif}} \frac{1+\cos \beta}{2}+\mathrm{I}_{\mathrm{glo}, \text { hor }} \rho_{\mathrm{g}} \frac{1-\cos \beta}{2}
$$

Where $\theta_{\mathrm{i}}$ is an incidence angle, an angle between the normal of plan and line from the sun to the plan, and $\rho_{\mathrm{g}}$ is the reflectivity of the ground [5].

For vertical surfaces (walls in this study), the angle $\beta$ is equal $90^{\circ}$, and then equation (6) simply reduces to:

$$
I_{\text {glo, tilt }}=I_{\text {dir }} \cos \theta_{i}+\frac{I_{\text {dif }}}{2}+\rho_{\mathrm{g}} \frac{I_{\text {glo, hor }}}{2}
$$

\subsection{The solar-air temperature model}

For opaque surfaces such as walls, the effect of solar radiation can be conveniently accounted for by considering outside air temperature to be higher by an amount equivalent to the effect of solar radiation. This is done by replacing the ambient temperature in the heat transfer relation through the walls with the sol-air temperature, $\mathrm{T}_{\text {sol-air }}$. It is defined as the equivalent outdoor air temperature that gives the same rate of heat flow to a surface. Equation (8) gives an expression of sol-air temperature.

$$
\mathrm{T}_{\text {sol-air }}=\mathrm{T}_{\mathrm{a}}+\frac{\alpha \mathrm{I}}{\mathrm{h}_{1}}+\frac{\Delta \mathrm{q}_{\mathrm{ir}}}{\mathrm{h}_{1}}
$$

Where $\Delta \mathrm{q}_{\mathrm{ir}}$ is a correction to infrared radiation transferred between surface and environment if the sky temperature is different from $\mathrm{T}_{\mathrm{a}}$, and has units of $\mathrm{W} / \mathrm{m}^{2}[6]$.

Because vertical surfaces receive longwave radiation from the ground, surrounding buildings, and from the sky, it is difficult to determine their accurate $\Delta \mathrm{q}_{\mathrm{ir}} / \mathrm{h}_{1}$ values [7]. When solar radiation intensity is high, surfaces of terrestrial objects usually have a higher temperature than the outdoor air; thus, their longwave radiation compensates to some extent for the sky's low emittance. Because of this, it is common practice to assume $\Delta \mathrm{q}_{\mathrm{ir}} / \mathrm{h}_{1}=0$ for vertical surfaces [7].

For vertical surfaces, equation (8) will be:

$$
\mathrm{T}_{\mathrm{sol}-\mathrm{air}}=\mathrm{T}_{\mathrm{a}}+\frac{\alpha \mathrm{I}}{\mathrm{h}_{1}}
$$

Then, equation (3) can be written as: 


$$
-\mathrm{k} \frac{\partial \mathrm{T}(0, \mathrm{t})}{\partial \mathrm{x}}=\mathrm{h}_{1}\left(\mathrm{~T}_{\text {sol, air }}-\mathrm{T}(0, \mathrm{t})\right)
$$

\subsection{The ambient air temperature model}

Many models are available to evaluate the ambient air temperature, by applying them at a given location. One of the most models used to predict ambient air temperature is the monthly averaged temperature model proposed by Satyamurty and Babu [8]. The correlation developed to predict the hourly ambient temperature in terms of maximum and minimum temperatures of the day for a wide range of locations. This model has been used in this study with local weather data of Tripoli.

This model gives an expression of hourly ambient temperature at time $t$ (taken in hours) as:

$$
T_{a}(t)=A-B \cos \left(2 \pi(\bar{t})^{D}\right)-F
$$

Where:

$$
\begin{aligned}
& (\overline{\mathrm{t}})^{\mathrm{D}}=\left\{\begin{array}{ll}
\left(\mathrm{t}+24-\mathrm{t}_{\min }\right) / 24 & \text { if }\left(\mathrm{t}<\mathrm{t}_{\min }\right) \\
\left(\mathrm{t}-\mathrm{t}_{\min }\right) / 24 & \text { if }\left(\mathrm{t} \geq \mathrm{t}_{\min }\right)
\end{array}\right\} \\
& \mathrm{A}=0.5\left(\mathrm{~T}_{\max }+\mathrm{T}_{\text {min }}\right) \\
& \mathrm{B}=0.5\left(\mathrm{~T}_{\max }-\mathrm{T}_{\min }\right) \\
& \mathrm{D}=\frac{\ln (2)}{\ln \left(24 /\left(\mathrm{t}_{\text {max }}-\mathrm{t}_{\text {min }}\right)\right)} \\
& F=\left\{\begin{array}{ll}
0.22 & \text { if }(t<18) \\
1.25 & \text { if }(\mathrm{t} \geq 18)
\end{array}\right\}
\end{aligned}
$$

\subsection{Numerical model}

The governing equation, equation (1), is a partial differential equation, of parabolic type, with two first-order ordinary differential equations representing the boundary conditions, equations (4) and (10); in addition to that, the initial condition is given by equation (5). The set of governing equations are solved by employing the finite difference method, using a fully implicit approach. The central approximation is used to discretize the space derivative and forward difference approximation for the time derivative. Figure 2 illustrate the discretization of the wall layers.

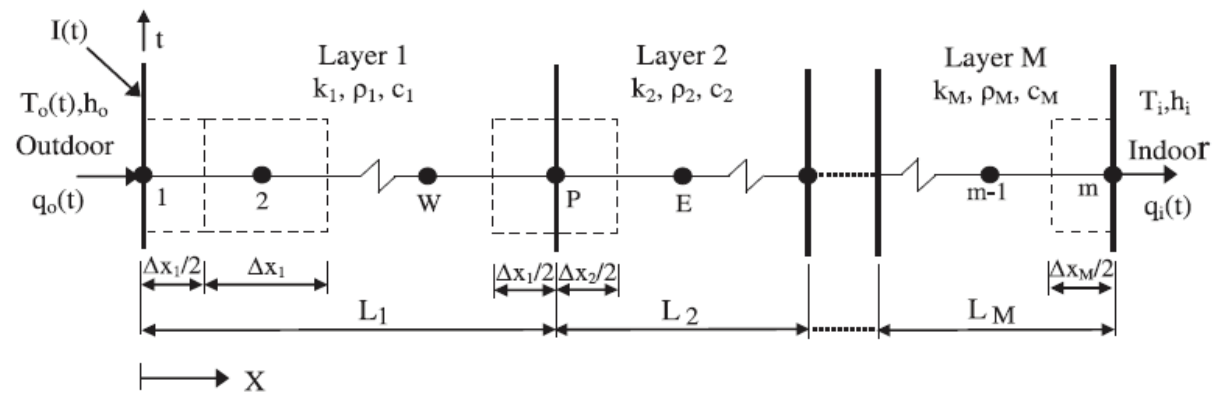

Figure (2). The discretization of the wall construction 
The general finite difference equation for any interior node in the same layer:

$$
-\mathrm{FT}_{\mathrm{i}-1}^{\mathrm{n}+1}+(1+2 \mathrm{~F}) \mathrm{T}_{\mathrm{i}}^{\mathrm{n}+1}-\mathrm{FT}_{\mathrm{i}+1}^{\mathrm{n}+1}=\mathrm{T}_{\mathrm{i}}^{\mathrm{n}}
$$

Where $\mathrm{F}$ is the Fourier number:

$$
\mathrm{F}=\frac{\alpha \Delta \mathrm{t}}{(\Delta \mathrm{x})^{2}}
$$

A very simple approach to discretize the outside boundary condition equation, equation (10), is to use forward differencing; but the results are only first-order accurate, $\mathrm{O}(\Delta \mathrm{x})$. A second-order accurate, , $\mathrm{O}[(\Delta \mathrm{x})]^{2}$ differencing of this boundary condition is possible if central differencing is used to discretize the first derivative at this boundary. To apply the central differencing, we consider a fictitious node ( 0 ) with a fictitious temperature, obtained by extending the region by to the left, as illustrated in Figure 3.

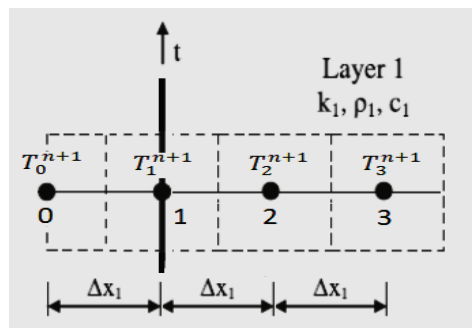

Figure (3) Fictitious node for the outside boundary condition

Equation (17) is evaluated for $\mathrm{i}=1$ and the resulting fictitious temperature $\mathrm{T}_{0}^{\mathrm{n}+1}$ is eliminated by utilizing the equation obtained by discretizing the boundary condition with central differences about the same node as follows:

$$
-\mathrm{FT}_{0}^{\mathrm{n}+1}+\left(1+2 \mathrm{~F}_{1}\right) \mathrm{T}_{1}^{\mathrm{n}+1}-\mathrm{F}_{1} \mathrm{~T}_{2}^{\mathrm{n}+1}=\mathrm{T}_{1}^{\mathrm{n}}
$$

Discretizing equation (10) by applying the fictitious node concept yields:

$$
\mathrm{T}_{2}^{\mathrm{n}+1}-\mathrm{T}_{0}^{\mathrm{n}+1}=\frac{2 \mathrm{~h}_{1} \Delta \mathrm{x}}{\mathrm{k}}\left(\mathrm{T}_{1}^{\mathrm{n}+1}-\mathrm{T}_{\mathrm{sol}}^{\mathrm{n}+1}\right)
$$

Substitute equation (20) in equation (19) and rearranging we get the finite difference equation for the outside wall surface boundary condition $($ at $\mathrm{x}=0)$ :

$$
\left(1+2 \mathrm{~F}_{1}+\mathrm{F}_{1} \mathrm{~B}_{\mathrm{i}, 1}\right) \mathrm{T}_{1}^{\mathrm{n}+1}-2 \mathrm{~F}_{1} \mathrm{~T}_{2}^{\mathrm{n}+1}=2 \mathrm{~F}_{1} \mathrm{~B}_{\mathrm{i}, 1} \mathrm{~T}_{\mathrm{sol}}^{\mathrm{n}+1}+\mathrm{T}_{1}^{\mathrm{n}}
$$

Where $\mathrm{B}_{\mathrm{i}}$ is the Biot number.

The same procedure is applied in the discretization of the outside boundary condition. Applying the fictitious node concept based on a constant heat flux on the inside surface, the finite difference equation for the inside wall surface $(\mathrm{x}=\mathrm{L})$ will be: 


$$
-2 \mathrm{~F}_{\mathrm{m}} \mathrm{T}_{\mathrm{m}-1}^{\mathrm{n}+1}+\left(1+2 \mathrm{~F}_{\mathrm{m}}+\mathrm{F}_{\mathrm{m}} \mathrm{B}_{\mathrm{i}, \mathrm{m}}\right) \mathrm{T}_{1 \mathrm{~m}}^{\mathrm{n}+1}=2 \mathrm{~F}_{\mathrm{m}} \mathrm{B}_{\mathrm{i}, \mathrm{m}} \mathrm{T}_{\mathrm{r}}+\mathrm{T}_{\mathrm{m}}^{\mathrm{n}}
$$

To discretize the interface between two different materials " $A$ and B " in contact, as shown in Figure 4, a procedure that is based on the continuity of heat flux at the interface is used. This procedure employs Taylor's expansion to deal with space derivatives of each layer separately.

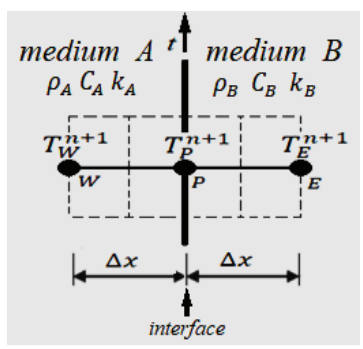

Figure (4). Discretization of the interface between two layers

The finite difference equation at each interface between two different layers will be:

$$
\begin{aligned}
-\frac{\mathrm{k}_{\mathrm{A}}}{\Delta \mathrm{x}} \mathrm{T}_{\mathrm{i}-1}^{\mathrm{n}+1}+\left(\frac{\rho_{\mathrm{A}} \mathrm{C}_{\mathrm{PA}} \Delta \mathrm{x}}{2 \Delta \mathrm{t}}+\frac{\rho_{\mathrm{B}} \mathrm{C}_{\mathrm{PB}} \Delta \mathrm{x}}{2 \Delta \mathrm{t}}+\frac{\mathrm{k}_{\mathrm{A}}}{\Delta \mathrm{x}}+\frac{\mathrm{k}_{\mathrm{B}}}{\Delta \mathrm{x}}\right) \mathrm{T}_{\mathrm{P}}^{\mathrm{n}+1}=\frac{2 \mathrm{~h}_{1} \Delta \mathrm{x}}{\mathrm{k}}\left(\mathrm{T}_{1}^{\mathrm{n}+1}-\mathrm{T}_{\mathrm{sol}}^{\mathrm{n}+1}\right) \\
=\left(\frac{\rho_{\mathrm{A}} \mathrm{C}_{\mathrm{PA}} \Delta \mathrm{x}}{2 \Delta \mathrm{t}}+\frac{\rho_{\mathrm{B}} \mathrm{C}_{\mathrm{PB}} \Delta \mathrm{x}}{2 \Delta \mathrm{t}}\right) \mathrm{T}_{\mathrm{P}}^{\mathrm{n}} .
\end{aligned}
$$

The system of finite difference equations obtained by applying equation (17) to the interior nodes, equation (21) for the node at the outside boundary of the wall, equation (22) for the node at the inside boundary of the wall, and equation (23) for each interface node between two different substances, is solved by the matrix inversion method.

\subsection{Estimation of cooling load temperature difference}

The cooling load $(\mathrm{Q})$ for a building through the walls is given by:

$$
\mathrm{Q}=\mathrm{UA}(\mathrm{CLTD})
$$

Where A is the surface area of the wall, and is the overall heat transfer coefficient, given by:

$$
\mathrm{U}=\left(\frac{1}{\mathrm{~h}_{1}}+\sum_{\mathrm{i}-1}^{\mathrm{n}} \frac{\mathrm{L}_{\mathrm{i}}}{\mathrm{k}_{\mathrm{i}}}+\frac{1}{\mathrm{~h}_{2}}\right)^{-1}
$$

Where $h_{1}\left(\mathrm{~W} /\left(\mathrm{m}^{2} . \mathrm{K}\right)\right)$ is the surface heat conductance at the outside surface of the wall, and is the surface heat conductance at the inside surface of the wall.

The cooling load at the inside surface can be obtained by applying the following equation:

$$
\mathrm{Q}=\mathrm{h}_{2} \mathrm{~A}\left(\mathrm{~T}_{\mathrm{L}, \mathrm{t}}-\mathrm{T}_{\mathrm{r}}\right)
$$

Where $\mathrm{T}(\mathrm{L}, \mathrm{t})$ is the inside surface temperature, and $\mathrm{T}_{\mathrm{r}}$ is the design indoor room temperature. 
Consequently, the CLTD can then be calculated using equations (24) and (26) as:

CLTD $=\frac{\mathrm{h}_{2}}{\mathrm{U}}\left(\mathrm{T}_{\mathrm{L}, \mathrm{t}}-\mathrm{T}_{\mathrm{r}}\right)$

The overall heat transfer coefficient and surface heat conductance both are properties of the wall and the ambient air; furthermore, the room temperature is assumed a known constant as a design condition. Thus, all variables in equation (27) are known except which evaluated by generating a temperature profile using the numerical model presented in this study.

The above calculations developed is used to solve the one-dimensional transient heat transfer problems. It is done by applying the concept of the finite difference method with several models (sol-air temperature, ambient air temperature, and solar radiation). The temperature profile through the wall can be obtained by applying the presented numerical model using MATLAB software package. Finally, the CLTD values can be estimated for any type of walls.

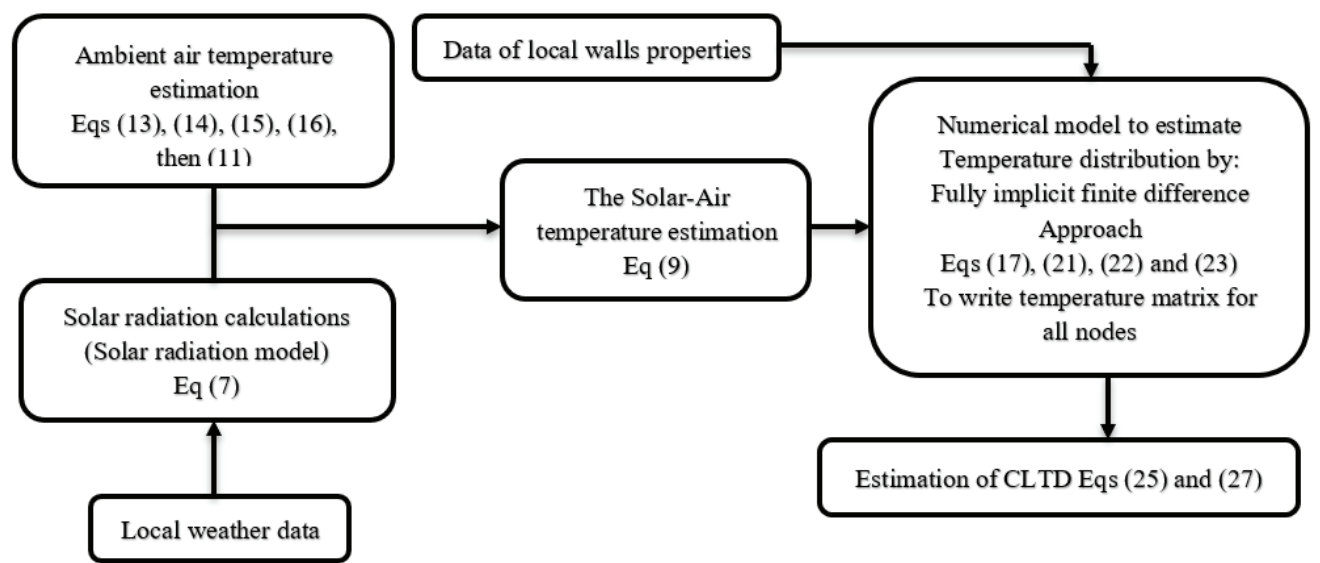

Figure (5). An algorithm for the used procedure / MATLAB programing

\section{RESULTS AND DISCUSSIONS}

The model developed in this study estimates the hourly cooling load temperature difference values, at any day of the year in any location. The model requires appropriate weather data such as the hourly values of outdoor temperature (including maximum and minimum values through the day, and their time of occurrence) and the specifications of the actual wall. MATLAB was used to build a computer program that simulates the model the results of which are presented here.

\subsection{Verification of the model}

Figure 6 illustrates the comparison between the values of CLTD presented in ASHRAE [9] and the values obtained by implementing the numerical model of this study. In this comparison, the wall is considered to have the following specifications:

- $\quad$ Outside resistance $\left(1 / \mathrm{h}_{1}=0.059 \mathrm{~m}^{2} . \mathrm{K} / \mathrm{W}\right)$.

- $20 \mathrm{~mm}$ plaster (outside).

- $200 \mathrm{~mm}$ low density concrete block (principal wall material).

- $20 \mathrm{~mm}$ plaster (inside).

- Inside resistance $\left(1 / \mathrm{h}_{2}=0.121 \mathrm{~m}^{2} . \mathrm{K} / \mathrm{W}\right)$. 
All thermal and physical properties are taken from ASHRAE [9]. The results presented in Figure (5) were generated using the following input data:

- $\quad$ Latitude: $40^{\circ} \mathrm{N}$.

- Outdoor maximum temperature: $35^{\circ} \mathrm{C}$ at $15: 00 \mathrm{~h}$.

- Outdoor minimum temperature: $23.4^{\circ} \mathrm{C}$ at $05: 00 \mathrm{~h}$.

- Indoor temperature (room temperature) is $25.5^{\circ} \mathrm{C}$.

- The daily range is $11.6^{\circ} \mathrm{C}$.

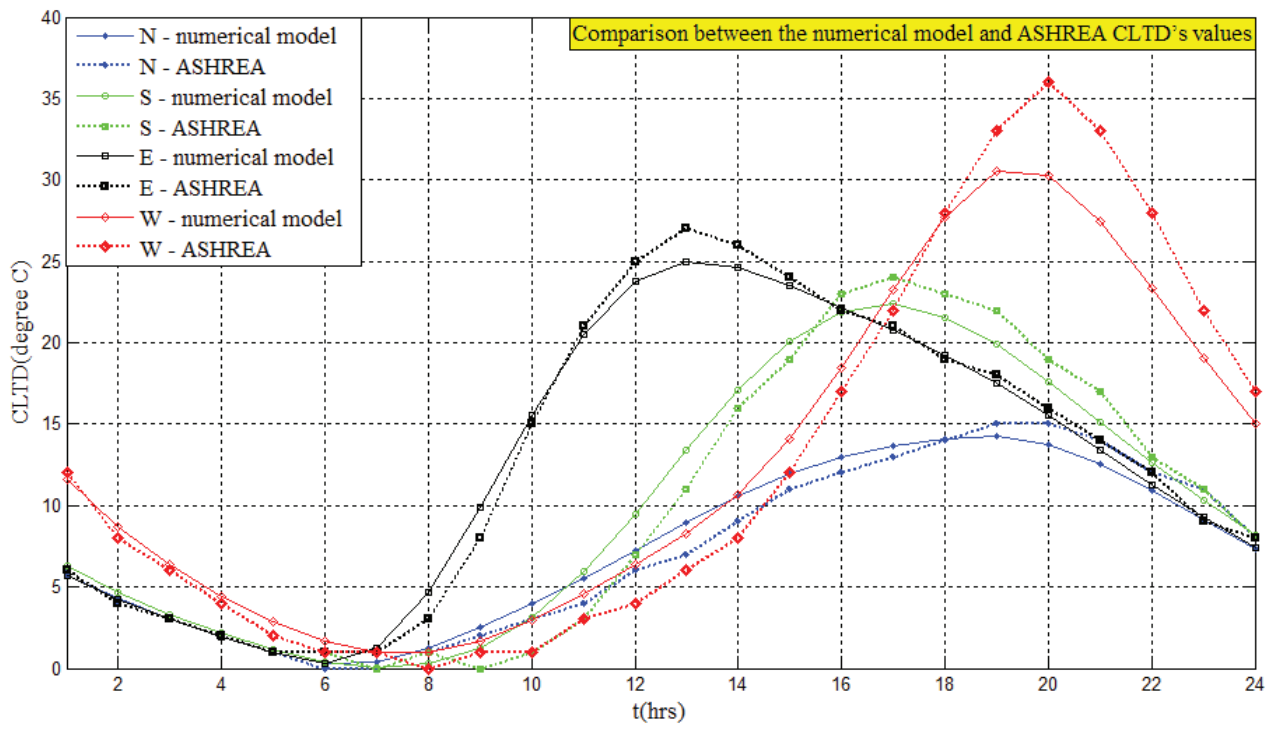

Figure (6). Comparison between estimated and ASHRAE CLTD values at $40^{\circ} \mathrm{N}$

It is noticed from Figure (6) that a good agreement exists between the values of CLTD obtained from ASHRAE [9] and CLTD values obtained in this study. In general, the error at most points fluctuates between $0.2 \%$ and $7.5 \%$, except at $08: 00 \mathrm{pm}$ when the wall is facing west, where the error could reach $15 \%$. The differences between the calculated and ASHRAE CLTD values can be attributed to several factors. ASHRAE categorizes each wall into a particular type (A, B, C, or D), but gives single CLTD values for all these four types, without making any distinction among them, which as a result, may involve some averaging of CLTD values. Furthermore, the differences in data sources, such as, the models used to calculate the solar radiation and ambient temperature, and the approximation in the numerical method that used in this study could contribute to the indicated differences, such as the truncation error in Taylor's series, etc... In general, obtained results are fairly acceptable, especially as they are obtained from simple calculation methods, and may be very useful in the case of the absence of measured and real data such as incident solar radiation values and ambient air temperature.

Based on the above results and their accuracy, it is possible to rely on the models that are presented in this research and they can be applied to Tripoli city in Libya of course by using the wall constructions types that are commonly used for constructing external walls in Libya, and the same climatic conditions of this city.

\subsection{Properties of local walls}

In Libya, hollow concrete blocks (H.C.B), limestone blocks (L.B), and hollow bricks (H.B), are the most commonly used types of materials for constructing external walls. Table (1) shows the details and specifications 
of different layers that make up the external wall in addition to the values of thermal resistance of the internal and external layers of air.

Table (1) Physical and thermal properties of three types of walls [10]

\begin{tabular}{|c|c|c|c|c|c|c|c|}
\hline & Wall Construction & $\begin{array}{c}\mathrm{L} \\
\mathrm{mm}\end{array}$ & $\begin{array}{c}\mathbf{k} \\
\mathrm{W} / \mathrm{m} \cdot \mathrm{K}\end{array}$ & $\begin{array}{c}\mathbf{R} \\
\mathbf{m}^{2} \cdot \mathrm{K} / \mathrm{W}\end{array}$ & $\begin{array}{c}\rho \\
\mathrm{kg} / \mathrm{m}^{3}\end{array}$ & $\begin{array}{c}\mathrm{C}_{\mathrm{p}} \\
\mathrm{kJ} /(\mathrm{kg} \cdot \mathrm{K})\end{array}$ & $\begin{array}{c}\alpha \\
\mathrm{m}^{2} / \mathrm{s}\end{array}$ \\
\hline \multirow{5}{*}{$\begin{array}{l}\text { Wall A } \\
\text { H.C.B }\end{array}$} & Inside resistance & - & - & 0.12 & - & 1.23 & - \\
\hline & Cement plaster & 20 & 0.72 & 0.0278 & 1860 & 840 & $4.61 \times 10^{-7}$ \\
\hline & $\begin{array}{l}\text { Hollow concrete } \\
\text { block }\end{array}$ & 200 & 1.038 & 0.1927 & 977 & 840 & $1.265 \times 10^{-6}$ \\
\hline & Cement plaster & 20 & 0.72 & 0.0278 & 1860 & 840 & $4.61 \times 10^{-7}$ \\
\hline & outside resistance & - & - & 0.044 & - & 1.23 & - \\
\hline \multirow{5}{*}{$\begin{array}{l}\text { Wall B } \\
\text { L.B }\end{array}$} & Inside resistance & - & - & 0.12 & - & 1.23 & - \\
\hline & Cement plaster & 20 & 0.72 & 0.0278 & 1860 & 840 & $4.61 \times 10^{-7}$ \\
\hline & limestone block & 200 & 1.731 & 0.1155 & 2240 & 845 & $8.732 \times 10^{-7}$ \\
\hline & Cement plaster & 20 & 0.72 & 0.0278 & 1860 & 840 & $4.61 \times 10^{-7}$ \\
\hline & outside resistance & - & - & 0.044 & - & 1.23 & - \\
\hline \multirow{5}{*}{$\begin{array}{l}\text { Wall C } \\
\text { H.B }\end{array}$} & Inside resistance & - & - & 0.12 & - & 1.23 & - \\
\hline & Cement plaster & 20 & 0.72 & 0.0278 & 1860 & 840 & $4.61 \times 10^{-7}$ \\
\hline & hollow brick & 200 & 0.920 & 0.2174 & 977 & 835 & $1.17 \times 10^{\wedge-6}$ \\
\hline & Cement plaster & 20 & 0.72 & 0.0278 & 1860 & 840 & $4.61 \times 10^{-7}$ \\
\hline & outside resistance & - & - & 0.044 & - & 1.23 & - \\
\hline
\end{tabular}

\subsection{Solar radiation results}

Figure 7 shows a clear comparison of the results (solar radiation profiles) obtained by using ASHRAE model for clear sky (solar model) with data measured practically by the Scientific Research and Renewable Energies Center in Tajora [11], for Tripoli on July $21^{\text {st }}$. A good agreement can be observed between the measured values and these results. It is possible to rely entirely on simulation models to estimate solar radiation profiles.

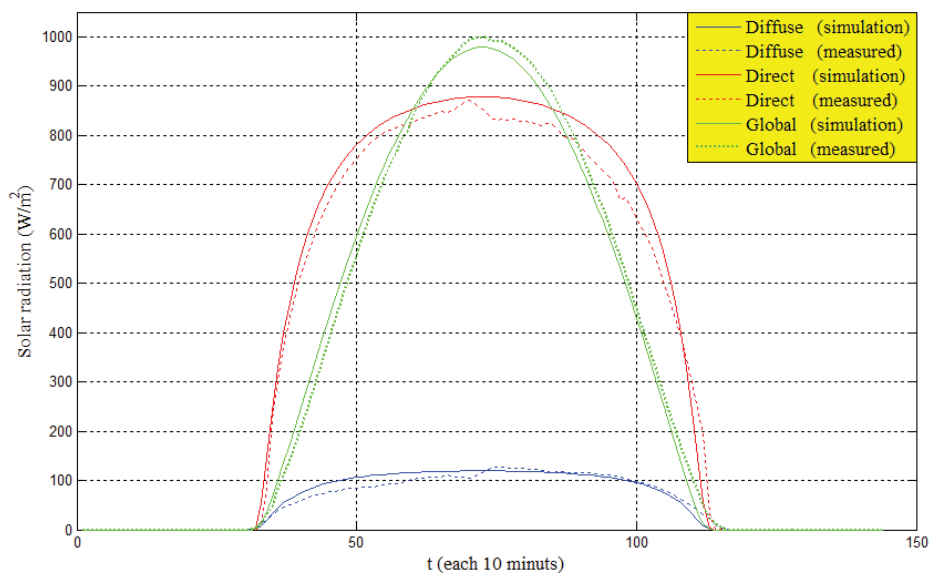

Figure (7). Measured and calculated radiation profiles on a horizontal surface in Tripoli. 


\subsection{Sol-air and ambient air temperatures}

The variation of the sol-air and ambient air temperatures are shown in Figure (8). These curves are estimated for Tripoli city - Libya on July $21^{\text {st }}$. The data used in sol-air and ambient air temperature models are based on real values of data. Including the maximum and minimum outdoor temperatures during the day, and the time they occur at (solar time). These values are taken from hourly data of air temperatures throughout the day, which are measured by the Scientific Research and Renewable Energies Center in Tajora [11]. These data are collected for the last three years (2016, 2017 and 2018), then taken as average through three years. The outdoor maximum temperature is and it occurs at 12:00 (solar time), with a daily range of. Also, the amount of solar radiation that is used directly in the calculation of sol-air temperature, which discussed in section (4.3).
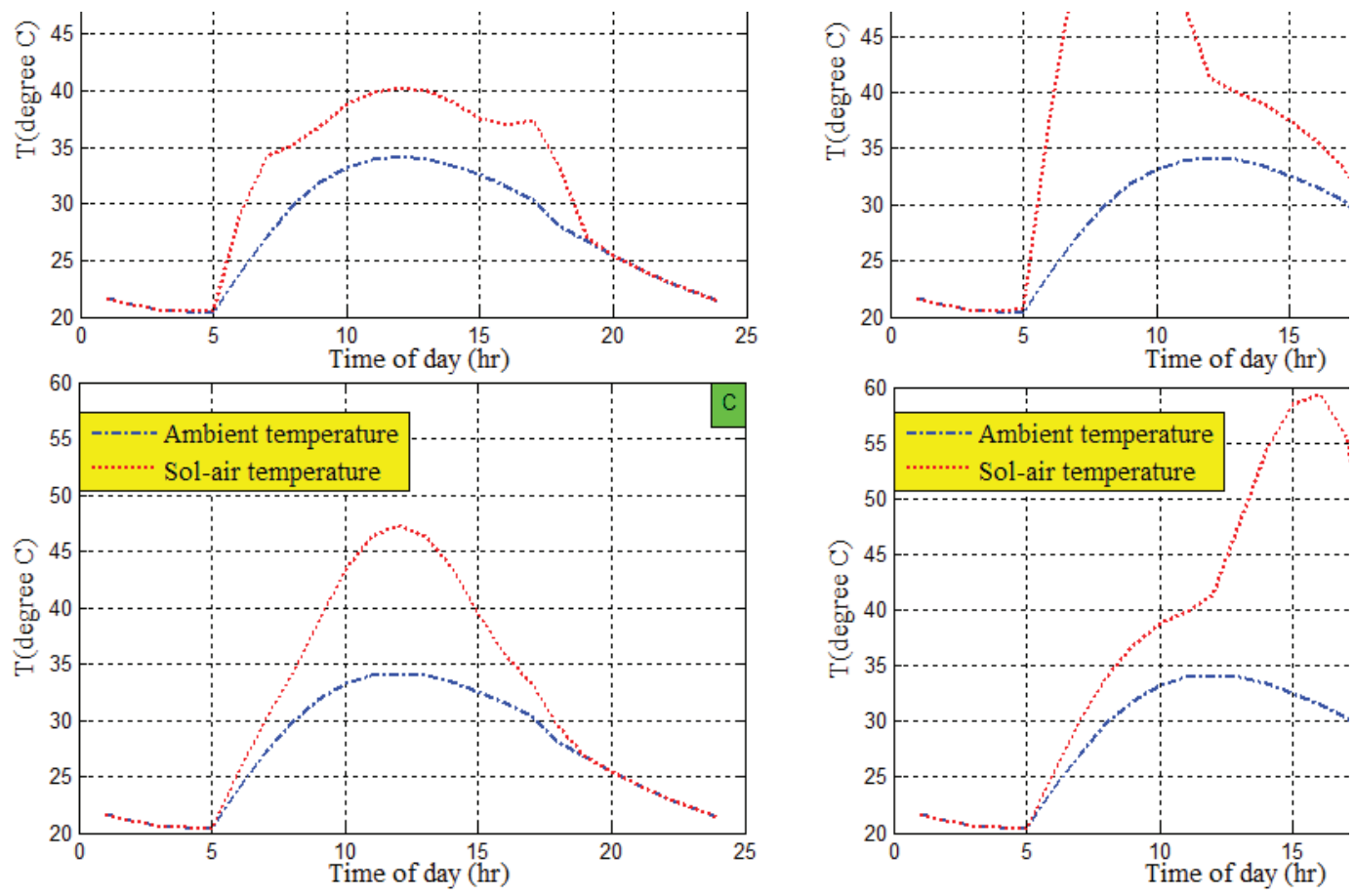

Figure (8). Sol-air and ambient air temperatures on July $21^{\text {st }}$ (A) North, (B) East, (C) South and (D) West

Based on these data, the sol-air and ambient air temperatures are evaluated and plotted in Figure 8 for the four main wall directions (north, east, south and west), where the ambient temperature is the same for all directions.

\subsection{Thermal behavior of walls under study}

Figure 9 illustrates the gradient of temperature through the wall at 16:00 for three types of wall constructions (where the maximum value of sol-air temperature occurs at this hour). In general, both layers of cement plaster have a temperature gradient that is higher than the block material's slope when the wall facing west, (first and last $20 \mathrm{~mm}$ of the wall thickness). For other directions, the temperature gradient profiles are almost the same. 

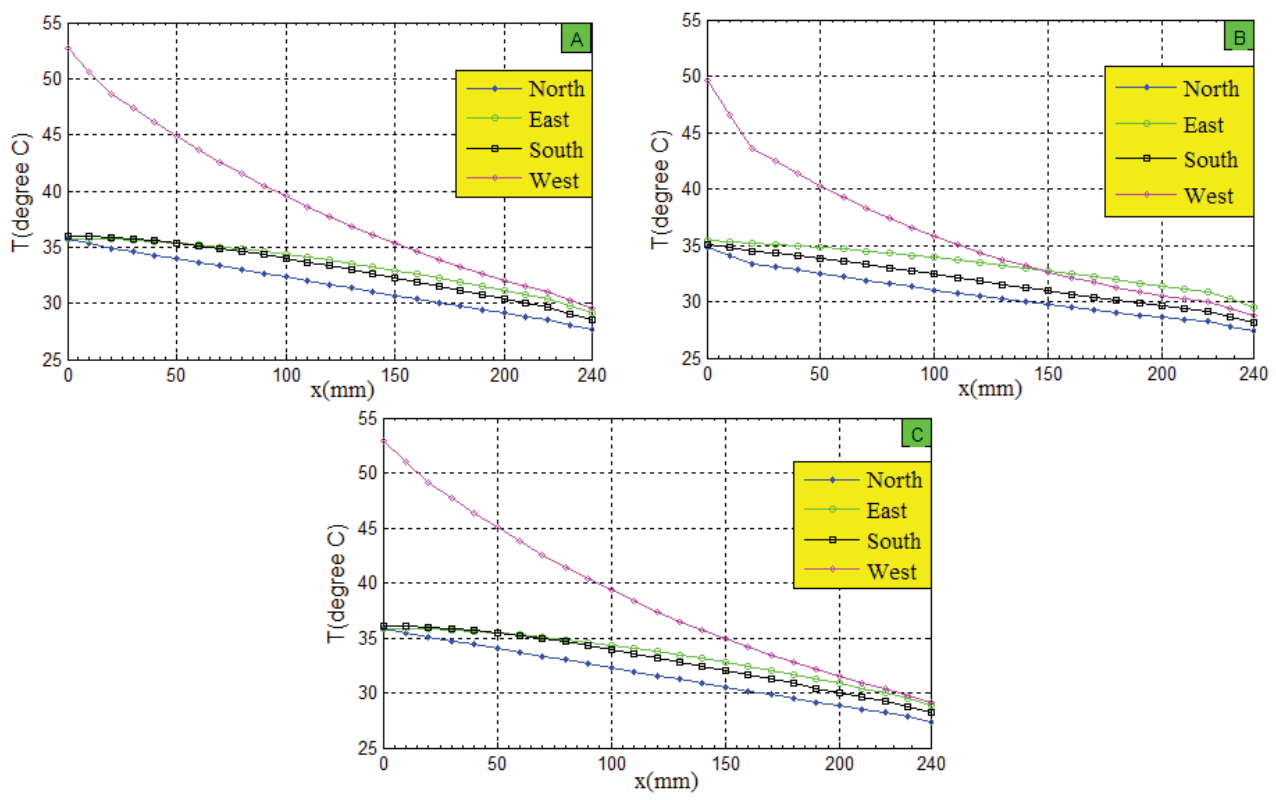

Figure (9). Temperature profile of different orientations of the three walls at 16.00 on July $21^{\text {st }}$ of walls (A) Hollow concrete block, (B) Limestone block and (C) Hollow brick.

The main reason for decreasing the temperature gradient through the main substance is the thermal resistance, which is higher than the resistance of cement plaster layers. The difference between the thermal resistance values of each layer can be noticed from Table 1. Despite the similar thermal behavior of the three types of walls, there are some minor differences in the second wall (Limestone block) Figure (8B). Although the limestone has high thermal conductivity compared to the two other types, this type has a delay in the response to the outside temperature changes, the reason behind that could be related to the high density and thermal mass. On the other hand, for the temperature of the inner surface of three types of walls, the hollow brick has the lowest inner temperature for all directions. It means that the slope of the temperature gradient of this type (hollow brick) is higher than the two other types, which makes this type to be the best with regard to thermal characteristics (high thermal resistance).

Figure 10 describes the temperature at the inner surfaces of the three types of walls in the four directions. It is very helpful to study and present the temperature changes at the inside surface during the day of $21^{\text {st }}$ of July, where the inner surface temperature is directly related to the estimation of the CLTD values in the model presented in this research.

Similar thermal behavior can be observed for the hollow concrete block and hollow brick block walls, where the temperature at the inner surface of the two types are almost the same with minor differences, for few hours, estimated to be about .

From Figure (10), the hollow brick has the lowest values of temperature at the inner surface (almost all the day) which means a lower amount of energy consumption in air conditioning systems compared to the other two types (this means that it has the smallest temperature difference between inner surface temperature and room temperature ()). The hollow concrete block is considered to be the worst in terms of thermal loads with regard to designing the air conditioning and cooling systems, where the temperature at the inner surface of the wall is always greater than the other two types except for the north wall surface. 

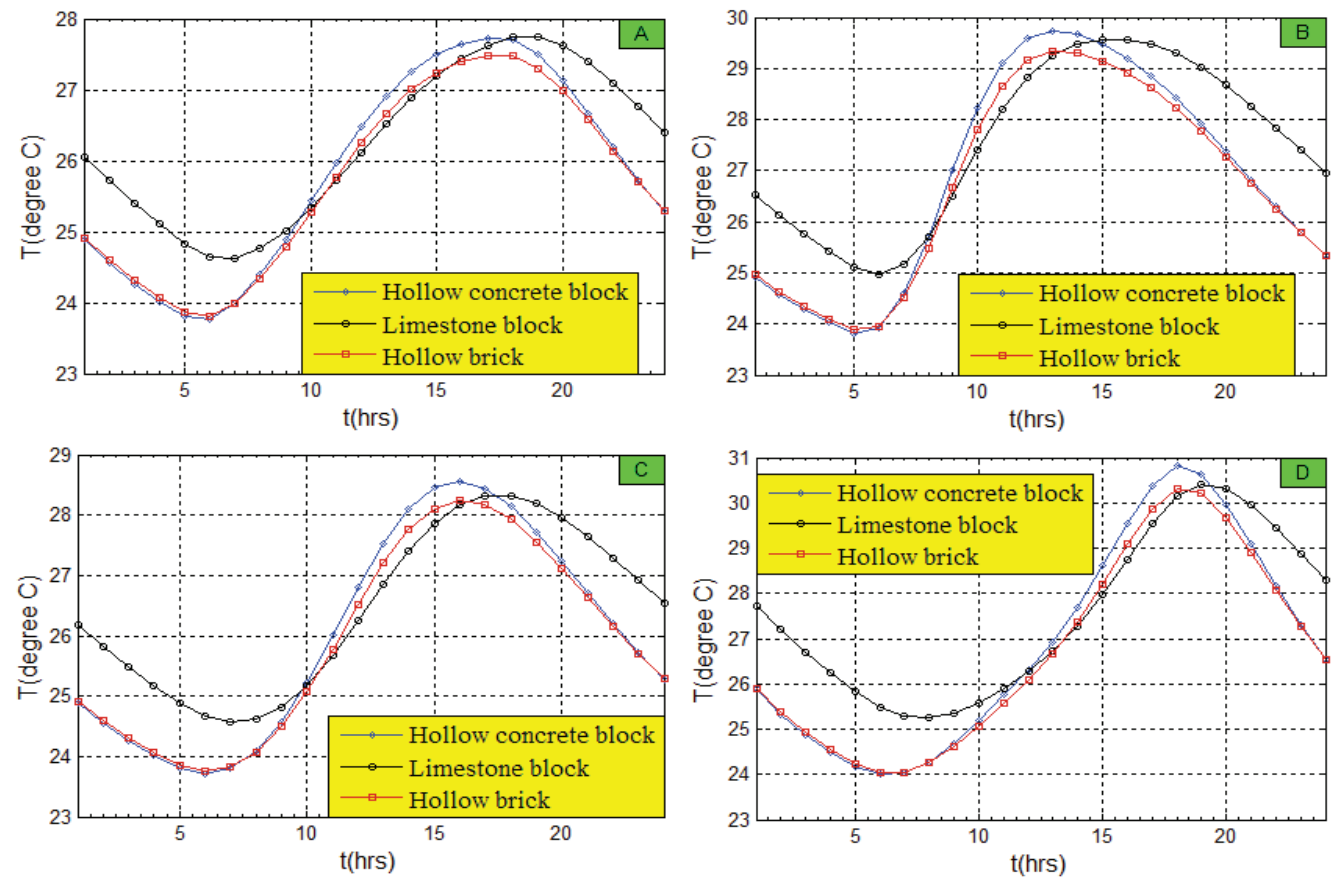

Fig (10) Temperature profiles at the inner surfaces of the three walls in four directions; (A) North, (B) East, (C) South and (D) West.

In general, from Figures (9) and (10) it can be noted that the limestone has the characteristic of storage energy inside it, because of the high density, this explains the slow response to the temperature changes at the outside surface of the wall. In contrast to the other two walls, it is easy to observe the fast response of the temperature at the inside surface to the changes of solar-air temperature throughout the day.

\subsection{Estimated CLTD values for Tripoli, Libya}

CLTD data has been generated for Tripoli, Libya $\left(32.54^{\circ} \mathrm{N} 13.18\right)$. This has been plotted by applying the model presented in this work. Figure (11) shows the CLTD values described using four curves for the four main directions.

From Figure 11 (A, B, C and D), it is clear to note that the hollow concrete block and hollow brick block walls have CLTD values which are almost the same with a small difference (about) for few hours during the day. Compared to the limestone block wall, the hollow concrete block and hollow brick block walls have large differences between the maximum and minimum CLTD values during the day, which is about in both these types, while the difference is about for the wall of limestone block. For these three types of walls, the difference between maximum and minimum values of CLTD occurs when the wall facing west.

Table (2) includes the CLTD values estimated using the numerical model presented in this study. These values were calculated for the city of Tripoli under the local specific conditions of this city, including the values of solar radiation and the maximum and minimum temperature during the day. These values are estimated for the $21^{\text {st }}$ of July. This model enables the user to calculate and estimate the values of CLTD for any day of the year, as well as for any region, taking into account the need to provide some important data such as temperatures during the day on which the values of CLTD is to be calculated. 


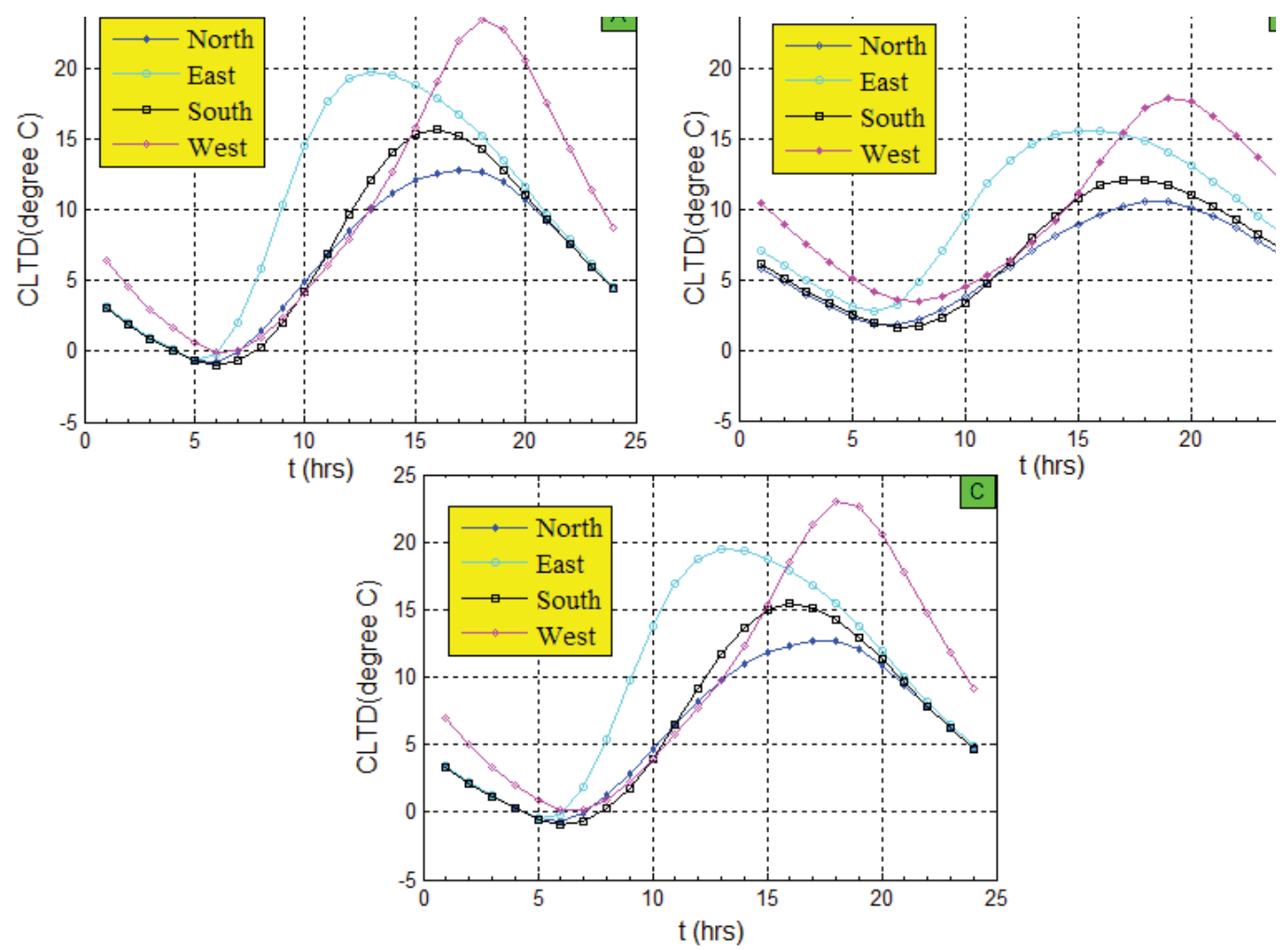

Figure (11). Estimated CLTD values of the three types of walls (A) Hollow concrete block, (B) Limestone block and (C) Hollow brick block.

Notes on tables:

No similar walls in ASHRAE for the studied local types (Limestone block and Hollow brick).

Direct application of data:

- Dark surface (for solar radiation absorption).

- Indoor designed temperature of $24{ }^{\circ} \mathrm{C}$.

- Outdoor maximum temperature of $34.4^{\circ} \mathrm{C}$ [10] with a mean temperature of $27.5^{\circ} \mathrm{C}$ and a daily range of $13.8^{\circ} \mathrm{C}$.

- Solar radiation typical of clear day on 21st day of July.

- Outside surface film resistance of 0.059 .

- Inside surface resistance of 0.12 . 
Table (2). CLTD values of local walls at Tripoli on July $21^{\text {st }}$

\begin{tabular}{|c|c|c|c|c|c|c|c|c|c|c|c|c|c|c|c|c|c|c|c|c|c|c|c|c|c|c|c|c|}
\hline \multirow{2}{*}{ 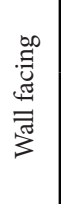 } & \multicolumn{24}{|c|}{ Solar time, $\mathrm{h}$} & \multirow{2}{*}{ 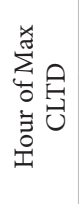 } & \multirow{2}{*}{ 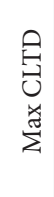 } & \multirow{2}{*}{ 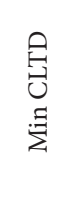 } & \multirow{2}{*}{ 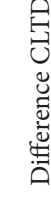 } \\
\hline & $\begin{array}{l}\stackrel{8}{0} \\
0\end{array}$ & 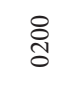 & ి్లి & \& & 웅 & \& & $\begin{array}{l}\stackrel{8}{0} \\
\text { Oे }\end{array}$ & $\begin{array}{l}8 \\
: \\
8\end{array}$ & ஃ̊․ & \&ి & $\stackrel{8}{\Xi}$ & 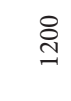 & 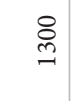 & 号 & $\begin{array}{l}8 \\
0 \\
10\end{array}$ & $\underset{8}{8}$ & $\stackrel{8}{\stackrel{2}{1}}$ & $\stackrel{8}{\infty}$ & ஓ & ¿̊․ & 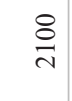 & $\begin{array}{l}\text { ते } \\
\text {. }\end{array}$ & 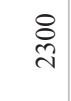 & ষ্ণ & & & & \\
\hline \multicolumn{25}{|c|}{ Wall A (hollow concrete block), } & & & & \\
\hline NE & 2.9 & 1.8 & 0.8 & 0.0 & -0.7 & -0.4 & 1.6 & 4.9 & 8.6 & 11.8 & 14.0 & 15.3 & 15.9 & 16.1 & 16.0 & 15.6 & 14.9 & 13.8 & 12.4 & 10.7 & 9.0 & 7.3 & 5.7 & 4.2 & 14 & 16.1 & -0.7 & 16.8 \\
\hline $\mathbf{E}$ & 3.2 & 2.0 & 1.0 & 0.1 & -0.6 & -0.2 & 2.0 & 5.9 & 10.3 & 14.5 & 17.6 & 19.2 & 19.7 & 19.4 & 18.8 & 17.8 & 16.7 & 15.2 & 13.5 & 11.6 & 9.7 & 7.9 & 6.2 & 4.6 & 13 & 19.7 & -0.6 & 20.3 \\
\hline SE & 3.1 & 1.9 & 0.9 & 0.1 & -0.7 & -0.6 & 0.7 & 3.5 & 7.1 & 10.9 & 14.2 & 16.6 & 17.9 & 18.2 & 17.9 & 17.2 & 16.2 & 14.9 & 13.2 & 11.4 & 9.5 & 7.7 & 6.1 & 4.5 & 14 & 18.2 & -0.7 & 18.9 \\
\hline $\mathbf{S}$ & 3.0 & 1.9 & 0.9 & 0.0 & -0.7 & -1.0 & -0.7 & 0.3 & 2.0 & 4.2 & 6.9 & 9.6 & 12.1 & 14.1 & 15.3 & 15.6 & 15.2 & 14.3 & 12.8 & 11.1 & 9.3 & 7.6 & 5.9 & 4.4 & 16 & 15.6 & -1 & 16.6 \\
\hline SW & 5.2 & 3.6 & 2.2 & 1.1 & 0.1 & -0.4 & -0.2 & 0.7 & 2.2 & 4.0 & 6.0 & 8.1 & 10.6 & 13.4 & 16.2 & 18.7 & 20.3 & 20.7 & 19.5 & 17.3 & 14.6 & 11.9 & 9.4 & 7.2 & 18 & 20.7 & -0.4 & 21.1 \\
\hline W & 6.5 & 4.6 & 3.0 & 1.7 & 0.6 & 0.0 & 0.1 & 0.9 & 2.4 & 4.1 & 6.0 & 7.9 & 10.1 & 12.7 & 15.8 & 19.1 & 21.9 & 23.4 & 22.8 & 20.5 & 17.5 & 14.3 & 11.4 & 8.7 & 18 & 23.4 & 0.0 & 23.4 \\
\hline \multirow{2}{*}{ 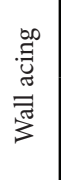 } & \multicolumn{24}{|c|}{ Solar time, $\mathbf{h}$} & \multirow{2}{*}{ 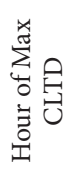 } & \multirow{2}{*}{ 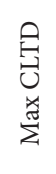 } & \multirow{2}{*}{ 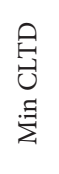 } & \multirow{2}{*}{ 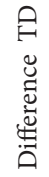 } \\
\hline & \begin{tabular}{l}
8 \\
\hdashline \\
0
\end{tabular} & 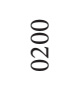 & ষ্ণ & ঃ & 응 & \&: & 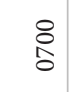 & $\begin{array}{l}8 \\
8 \\
0\end{array}$ & ஃ̊ & \&ి & 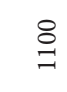 & 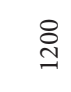 & 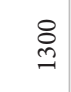 & 号 & $\begin{array}{l}8 \\
10\end{array}$ & $\begin{array}{l}8 \\
8 \\
0\end{array}$ & $\stackrel{8}{\stackrel{2}{1}}$ & $\underset{\infty}{8}$ & ஓి & ஓ̊ & $\frac{8}{\stackrel{\Xi}{(}}$ & $\begin{array}{l}\text { సి } \\
\text {. }\end{array}$ & $\begin{array}{l}\stackrel{\overbrace{}}{0} \\
\text { ते }\end{array}$ & ষ্ণ & & & & \\
\hline \multicolumn{25}{|c|}{ Wall B (Limestone block), } & & & & \\
\hline $\mathbf{N}$ & 5.7 & 4.8 & 3.9 & 3.1 & 2.3 & 1.8 & 1.8 & 2.1 & 2.8 & 3.7 & 4.8 & 5.9 & 7.0 & 8.0 & 8.9 & 9.6 & 10.1 & 10.5 & 10.5 & 10.1 & 9.5 & 8.6 & 7.7 & 6.7 & 10.5 & 18,19 & 1.8 & 8.7 \\
\hline $\mathrm{NE}$ & 6.3 & 5.3 & 4.4 & 3.5 & 2.7 & 2.3 & 2.8 & 4.1 & 5.9 & 7.9 & 9.6 & 10.9 & 11.9 & 12.5 & 13.0 & 13.2 & 13.2 & 12.9 & 12.4 & 11.6 & 10.7 & 9.6 & 8.5 & 7.4 & 13.2 & 16,17 & 2.3 & 10.9 \\
\hline $\mathbf{E}$ & 7.1 & 6.0 & 4.9 & 4.0 & 3.1 & 2.7 & 3.2 & 4.8 & 7.0 & 9.5 & 11.8 & 13.5 & 14.2 & 15.3 & 15.5 & 15.5 & 15.3 & 14.8 & 14.0 & 13.0 & 11.9 & 10.7 & 9.5 & 8.3 & 15.5 & 15,16 & 2.7 & 12.8 \\
\hline SE & 6.7 & 5.7 & 4.7 & 3.7 & 2.9 & 2.4 & 2.5 & 3.5 & 5.1 & 7.2 & 9.3 & 11.3 & 12.7 & 13.6 & 14.2 & 14.4 & 14.3 & 13.9 & 13.3 & 12.4 & 11.3 & 10.2 & 9.1 & 7.9 & 14.4 & 16 & 2.4 & 12 \\
\hline$S$ & 6.1 & 5.1 & 4.2 & 3.3 & 2.5 & 1.9 & 1.6 & 1.7 & 2.3 & 3.3 & 4.7 & 6.3 & 8.0 & 9.5 & 10.8 & 11.6 & 12.1 & 12.1 & 11.7 & 11.0 & 10.2 & 9.2 & 8.2 & 7.1 & 12.1 & 17,18 & 1.6 & 10.5 \\
\hline SW & 8.9 & 7.6 & 6.4 & 5.2 & 4.2 & 3.4 & 2.9 & 2.9 & 3.3 & 4.0 & 4.9 & 6.1 & 7.5 & 9.3 & 11.2 & 13.1 & 14.7 & 15.7 & 16.0 & 15.5 & 14.5 & 13.2 & 11.8 & 10.3 & 16 & 19 & 2.9 & 13.1 \\
\hline
\end{tabular}




\begin{tabular}{|c|c|c|c|c|c|c|c|c|c|c|c|c|c|c|c|c|c|c|c|c|c|c|c|c|c|c|c|c|}
\hline \multirow{2}{*}{ 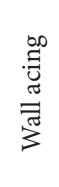 } & \multicolumn{24}{|c|}{ Solar time, $h$} & \multirow{2}{*}{ 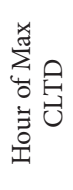 } & \multirow{2}{*}{ 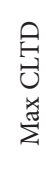 } & \multirow{2}{*}{$\begin{array}{l}\Theta \\
\stackrel{\exists}{\Xi} \\
\Xi\end{array}$} & \multirow{2}{*}{ 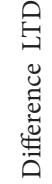 } \\
\hline & $\frac{8}{\circ}$ & ¿্ণ & రి & 용 & 옹 & : & 옹 & \& & ஃ̊ & \&ి & 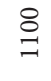 & 옥 & ஓి & \& & $\begin{array}{l}8 \\
\stackrel{1}{1}\end{array}$ & 윰 & 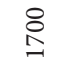 & 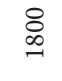 & ஓ̊ & ஓ্ণ & $\stackrel{8}{\stackrel{\Xi}{\sim}}$ & స్ & $\begin{array}{l}\stackrel{8}{2} \\
\text { }\end{array}$ & $\stackrel{8}{\stackrel{+}{+}}$ & & & & \\
\hline & \multicolumn{24}{|c|}{ Wall C (hollow brick block), } & & & & \\
\hline $\mathbf{N}$ & 3.3 & 2.2 & 1.1 & 0.3 & -0.5 & -0.7 & 0.0 & 1.2 & 2.9 & 4.6 & 6.5 & 8.2 & 9.7 & 10.9 & 11.8 & 12.3 & 12.6 & 12.6 & 12.0 & 10.9 & 9.4 & 7.8 & 6.2 & 4.7 & 12.6 & 17,18 & -0.7 & 13.3 \\
\hline NE & 3.2 & 2.1 & 1.1 & 0.2 & -0.5 & -0.3 & 1.5 & 4.5 & 8.1 & 11.3 & 13.6 & 15.0 & 15.7 & 15.9 & 15.9 & 15.5 & 14.9 & 13.9 & 12.6 & 11.0 & 9.3 & 7.6 & 6.0 & 4.5 & 15.9 & 14,15 & -0.5 & 16.4 \\
\hline $\mathbf{E}$ & 3.5 & 2.3 & 1.2 & 0.3 & -0.4 & -0.2 & 1.8 & 5.4 & 9.7 & 13.8 & 17.0 & 18.8 & 19.4 & 19.3 & 18.7 & 17.9 & 16.8 & 15.4 & 13.7 & 11.9 & 10.0 & 8.2 & 6.5 & 4.9 & 19.4 & 13 & -0.4 & 19.8 \\
\hline SE & 3.4 & 2.2 & 1.2 & 0.3 & -0.5 & -0.5 & 0.7 & 3.2 & 6.6 & 10.3 & 13.6 & 16.1 & 17.5 & 17.9 & 17.8 & 17.2 & 16.3 & 15.0 & 13.4 & 11.7 & 9.8 & 8.1 & 6.4 & 4.8 & 17.9 & 14 & -0.5 & 18.4 \\
\hline $\mathbf{S}$ & 3.3 & 2.1 & 1.1 & 0.2 & -0.5 & -0.9 & -0.7 & 0.3 & 1.8 & 3.9 & 6.5 & 9.2 & 11.7 & 13.7 & 15.0 & 15.4 & 15.2 & 14.3 & 12.9 & 11.3 & 9.6 & 7.9 & 6.2 & 4.7 & 15.4 & 16 & -0.9 & 16.3 \\
\hline SW & 5.6 & 4.0 & 2.6 & 1.4 & 0.4 & -0.2 & -0.1 & 0.7 & 2.0 & 3.8 & 5.7 & 7.8 & 10.2 & 12.9 & 15.7 & 18.2 & 19.9 & 20.4 & 19.5 & 17.4 & 14.9 & 12.3 & 9.8 & 7.6 & 20.4 & 18 & -0.2 & 20.6 \\
\hline $\mathbf{W}$ & 6.9 & 5.0 & 3.4 & 2.0 & 0.9 & 0.2 & 0.2 & 0.9 & 2.2 & 3.9 & 5.8 & 7.6 & 9.7 & 12.3 & 15.3 & 18.5 & 21.4 & 23.0 & 22.6 & 20.6 & 17.8 & 14.8 & 11.9 & 9.2 & 23 & 18 & 0.2 & 23.2 \\
\hline
\end{tabular}


The types of wall constructions attached in the ASHRAE [9] are not very similar to the local ones. Therefore, the comparison between calculated and ASHRAE [9] CLTD values could not be done. But there is one or two types of walls in ASHRAE [9] that can be approximated to be as a hollow concrete block wall that exists in Libya, which is mentioned in ASHRAE as the high-density concrete block. Both of them (hollow concrete block and high-density concrete block) have some resemblances in their properties.

Table (3) shows the comparison of the maximum values of CLTD between the computed and ASHRAE [9] values. A fairly good agreement can be noticed between the maximum values except for some directions such as West and Southwest, where the difference is approximately six degrees in both directions, noting that there is a time difference of about one or two hours for the scheduled CLTD values.

Table (3) The maximum calculated and ASHRAE CLTD values for hollow concrete block.

\begin{tabular}{|l|c|c|c|c|c|c|c|c|}
\hline & N & NE & E & SE & S & SW & W & NW \\
\hline Maximum CLTD (Estimated) & 12.8 & 16.1 & 19.4 & 18.2 & 15.6 & 20.7 & 23.4 & 19.5 \\
\hline Maximum CLTD (ASHRAE) & 12.6 & 15.6 & 21.6 & 21.6 & 19.6 & 26.6 & 29.6 & 22.6 \\
\hline Difference \% & 1.59 & 3.2 & 8.8 & 15.74 & 20.4 & 22.18 & 20.9 & 13.7 \\
\hline Hour of maximum CLTD (Estimated) & 17 & 14 & 13 & 14 & 16 & 18 & 18 & 18 \\
\hline Hour of maximum CLTD (ASHRAE) & $18-21$ & $13-18$ & $12-14$ & 14.15 & 17.18 & 19.20 & 20 & 20 \\
\hline The difference, hrs. & 3 & 2 & 0 & 0 & 1 & 1 & 2 & 2 \\
\hline
\end{tabular}

These small differences may be due to several reasons. First, the types of walls in the ASHRAE are grouped according to a certain range of thermal resistance; this range includes a set of walls. Thus, the values of CLTD that are scheduled in ASHRAE [9] for any group at any hour are averaged values at the indicated time for all walls. Second, the effect of differences in the values of solar radiation. Third, the assumptions and the different models used to estimate the CLTD values. Fourth, the difference in hourly temperature values used including the highest and lowest temperatures during the day used in the calculations.

It should be noted that the data of hourly temperatures used in this research (maximum and minimum temperatures) are taken from the Scientific Research and Renewable Energies Center in Tajora [10], which are more accurate than those calculated by models used in ASHRAE [9] for Libya.

\section{CONCLUSIONS}

Although, the CLTD method is one of the simplest methods for cooling load calculations, it provides reasonable and detailed results when compared with other methods. However, one downside of using this method is the limited number of walls which do not present effectively all commonly used wall constructions. This disadvantage has been tackled in this research by providing CLTD values of commonly used wall structures in Libya.

A numerical model was prepared and developed to deal with the one-dimensional, time-dependent heat transfer equation, using the fully implicit finite difference method. The results of using this model are very acceptable when compared with ASHRAE values of CLTD for the same wall construction. Some minor may be due to the different models used in calculations of solar radiation, sol-air temperature and ambient temperature, as well as the approximation used in the numerical methods. However, this model provides a simplified way to calculate CLTD values with acceptable accuracy.

The CLTD values for the three types of walls were calculated and tabulated so that the user can apply them immediately after selecting the type of wall and the time for calculation of cooling load. The CLTD values 
estimated in this research could be more realistic than those calculated using ASHRAE values since these values were calculated based on realistic data of the city of Tripoli, Libya.

The results of using the numerical model are very satisfactory which confirms the findings of previous researchers that it is possible to rely on this method to deal with cases that have similar nature where it is possible to use a transient, one-dimensional heat transfer model.

The limestone block provides the best thermal performance for un-conditioned buildings, because of the high thermal mass and low diffusivity, which is reflected in the slow response to thermal changes in the ambient conditions. This type of wall is followed by hollow brick, then the hollow concrete block. Furthermore, the hollow brick wall type can be considered the best for conditioned places, because of the high thermal resistance compared to limestone and hollow concrete blocks.

\section{REFERENCES}

[1]. Omer Z., Recep Y., 2015, Validation of periodic solution for computing CLTD (cooling load temperature difference) values for building walls and flat roofs. Journal of Energy, Vol. 82, Pages 758-768.

[2]. Bansal K., Chowdhury S., Gopal R., 2008, Development of CLTD values for buildings located in Kolkata, India. Journal of Applied Thermal Engineering, Vol. 28, pages 1127-1137.

[3]. Missoum A., Elmir M., Bouanini M., Draoui B., 2016, Numerical simulation of heat transfer through the building facades of buildings located in the city of Bechar. The international journal of multiphysics, Vol. 10, No. 4, pages 441-450.

[4]. Cengel Y., 2003, Heat transfer - A Practical Approach. Second edition, United State of America.

[5]. Somsak C., Khemmachart M., Boonyarit P., 2004, Development of cooling load temperature differential values for building envelopes in Thailand. Journal of the Chinese Institute of Engineers, Vol. 27, No. 5, Pages 677-688.

[6]. Felix U., Emmanuel S., 2013, Cooling load temperature differential values for buildings in Ghana. International journal of scientific and technology research, Vol. 2, No. 12, Pages 229-235.

[7]. ASHRAE handbook-fundamentals, 1985, United States of America.

[8]. Satyamurtys V., Babu S., 1999, Relative performance of correlations to estimate hourly ambient air temperature and development of a general correlation. International Journal of Energy Research, Vol. 23, No. 8, pages 663-673.

[9]. ASHRAE handbook-fundamentals, 1997, United States of America.

[10]. Elmzughi M., Alghoul S., Mashena M., 2020, Optimizing thermal insulation of external building walls in different climate zones in libya.

[11]. Weather data, Scientific Research and Renewable Energies center, 2016, 2017 and 2018, unpuplished, Tripoli.

[12] ـ ياسر فتحي ناصر، 2006، هندست الطاقت الشمسيت (التطبيقات الحراريت الفعالتة) ، الطبعت الأولى، جامعت سبها.

[13] Chen J., 2011, Physics of Solar Energy, Department of Applied Physics and Applied Mathematics, Columbia University, Canada.

[14] Carnahan B., Luther A., Wilkes O., 1990, Applied Numerical Methods. Reprint Edition, United State of America.

[15] Ozisik N., 1993, Heat Conduction. Second Edition, North Carolina.

[16] ASHRAE handbook-fundamentals, 1993, United States of America, 1993.

[17] Duffie A., Beckman A., 2013, Solar Engineering of Thermal Processes. Fourth Edition, United State of America.

[18] Sukhatme P., Nayak K., 1996, Solar Energy: Principles of Thermal Collection and Storage. Third Edition, New Delhi.

[19] McQuiston C., Parker D. 1994, Heating, Ventilating, and Air Conditioning, fourth edition, United States of America.

[20] Spitler D., Fisher E., Pedersen O., 1997, The Radiant Time Series Cooling Load Calculation Procedure, ASHRAE Transactions. Vol. 103, No. 2, pages 503-515.

[21]. Spitler D., McQuiston C., Lindsey K., 1993, The CLTD/SCL/CLF Cooling Load Calculation Method, ASHRAE Transactions. Vol. 99, No. 1, pages 183-192. 